
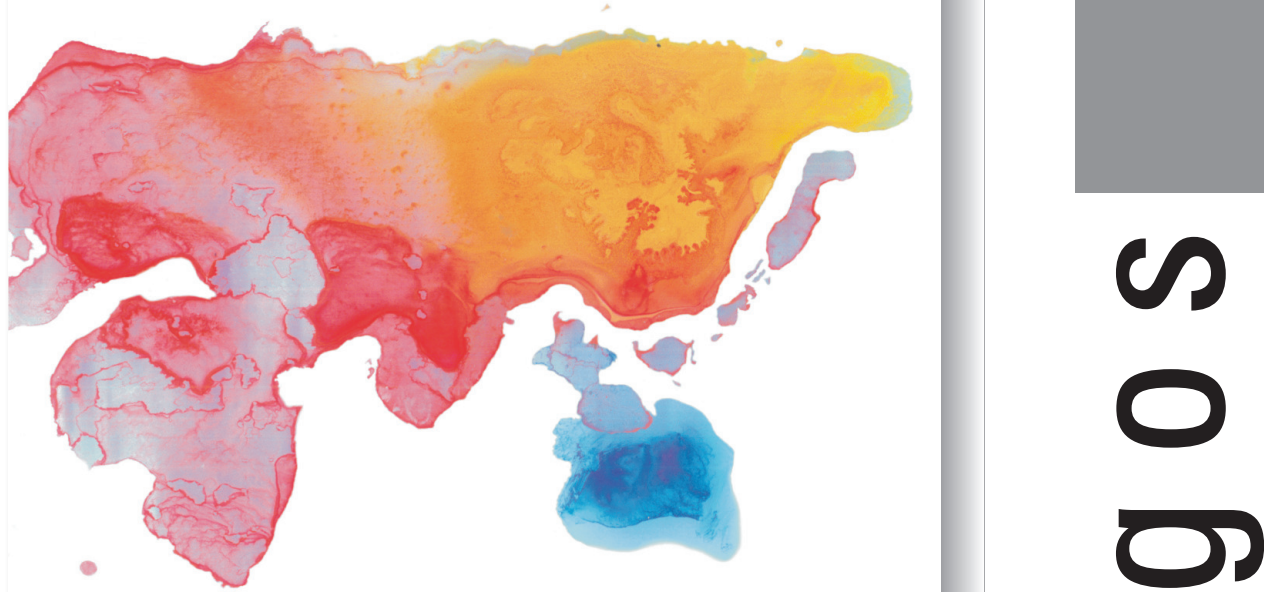

$\square$
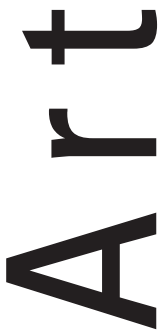


\title{
Análise sócio-ambiental da região do corredor Paranã-Pireneus - Estado de Goiás
}

\author{
Social-environmental analysis in the Paranã-Pireneus corridor - State of Goiás, Brazil \\ Flávia C. Ribeiro - CTE \\ flavia@cteengenharia.com.br \\ Cristiane da C. Vilela \\ criscvilela@hotmail.com \\ Fátima M. Kowata \\ fatmayumi@gmail.com \\ Manuel E. Ferreira - LAPIG/UFG \\ manuel@iesa.ufg.br
}

\section{RESUMO}

A savana brasileira, localmente conhecida como Cerrado, tem sido caracterizada como um dos ecossistemas mais ameaçados do mundo em termos de biodiversidade, com grande parte da área original convertida em atividades como a pastagem e a agricultura. Diante deste passivo ambiental, a criação de corredores ecológicos tem-se mostrado como uma das alternativas para preservar este ecossistema. Em Goiás, estado onde 0 Cerrado possui a sua maior representação, encontra-se em fase de criação o Corredor Ecológico Paranã-Pireneus, certamente uma das últimas áreas naturais com viabilidade ecológica no bioma Cerrado. Assim, neste trabalho realizamos uma caracterização sócio-ambiental do Corredor Ecológico Paraná-Pireneus, situado na porção nordeste do Estado de Goiás, com uma área aproximada de $66.000 \mathrm{~km}^{2}$. Dentre os resultados principais, apenas 17 municípios no corredor ecológico, de um total de 34, apresentam mais de $50 \%$ de remanescentes de Cerrado. No período de 2001 a 2006, os municípios de Cavalcante e Formosa foram os que mais apresentaram alertas de desmatamentos na área de estudo. Em dissonância com 0 ainda razoável percentual de Cerrado no corredor, esta área apresenta o menor índice de desenvolvimento humano $(0,68)$ quando comparado com as médias estadual $(0,73)$ e nacional $(0,74)$.

Palavras-chave: Cerrado, Análise sócio-ambiental, Corredor Ecológico Paranã-Pireneus.

\section{ABSTRACT}

The Brazilian savanna, locally known as Cerrado, has been characterized as one of threatened ecosystems in the world in terms of its high biodiversity, with a significant part of area converted into anthropic classes like pasture and agriculture. Ahead of this liability, the creation of ecological corridors has been considered as one of the alternatives to preserve this ecosystem. In Goiás, state with the major representation of Cerrado in Brazil, the Paranã-Pireneus Ecological corridor was created, certainly one of the last natural areas with ecological viability in the Cerrado biome. In this work we carryout a socialenvironmental characterization of the Paranã-Pireneus Ecological corridor, situated in the northeast portion of the State of Goiás, with an approach area of $66,000 \mathrm{~km}^{2}$. Amongst the main results, only 17 municipalities units in the ecological corridor (total of 34 ) present $50 \%$ of remnant native vegetation. In the period of 2001 to 2006, the Cavalcante and Formosa municipalities appear with the greater part of deforestations alerts. In disagreement with a still elevated occurrence of native vegetation, the study area presents a lower Human Development Index $(0.68)$ when compared with the state average $(0.73)$ and national average (0.74).

Key-words: Cerrado, socio-environmental analysis, Paranã-Pireneus Ecological Corridor 



\section{Introdução}

O bioma Cerrado é considerado ambientalmente como uma das savanas mais expressivas do mundo (et al., 2000), é dentre os biomas brasileiros, o mais ameaçado pelo uso e ocupação dos solos, sobretudo nas últimas décadas (et al., 1997). Cerca de 40\% de sua área original contínua (208 milhões de hectares) já foram convertidas, sendo normalmente associadas às atividades de pecuária e agricultura (Mantovani \& Pereira, 1998; Sano et al., 2002). Esta rápida transformação da paisagem é favorecida pelos baixos preços de terras na região, topografia favorável à maquinização da agricultura, além de incentivos governamentais como o POLOCENTRO e o PRODECER. Junto a isso, o Cerrado permanece desconhecido quanto ao seu valor ecológico. A sua rica biodiversidade, muitas vezes endêmica, é favorecida pela presença de três das maiores bacias hidrográficas da América do Sul (Paraná-Paraguai, Araguaia-Tocantins e São Francisco), além de uma grande diversidade de solos e geologia (1993).

Diante deste passivo ambiental, os Corredores Ecológicos vêm se compondo como um importante aliado a preservação da biodiversidade, ligado aos conceitos de desenvolvimento econômico e sócio-ambiental. Tais áreas interagem com a movimentação e dispersão de vida selvagem e de fluxo gênico, sustentando a conectividade entre habitats do referido ecossistema. Por outro lado, os corredores ecológicos são também importantes instrumentos de gestão ambiental, pois potencializam a cooperação entre variados níveis de governo e diferentes segmentos da sociedade civil (ex. IBAMA, SEMMA, ONGs, etc.). Assim, um dos principais objetivos de um corredor ecológico é a busca pela preservação da biodiversidade e o desenvolvimento humano (2004).

O presente estudo teve por objetivo caracterizar a região do Corredor Ecológico Paranã-Pireneus quanto aos aspectos políticos e sócio-ambientais. Especificamente, buscou-se analisar, de forma comparativa, os municípios inseridos na região do corredor, por meio de índices de desenvolvimento humano e econômico, além de dados temporais de desmatamentos (2001 a 2006), obtidos por imagens de satélites. 


\section{Fundamentação teórica}

\section{Os Corredores Ecológicos}

Na relação histórica entre sociedade e meio ambiente, são inúmeros os fatores de desequilíbrios ambientais oriundos do desenvolvimento humano, ao mesmo tempo em que cresce a necessidade de se manter os recursos básicos para a sobrevivência dos seres vivos. Esta necessidade ambiental incentiva ações políticas no sentido de se criar áreas legalmente protegidas e representativas da vida silvestre no planeta (et al., 2000).

A transformação dos ambientes naturais em meios antropizados (desmatamentos, queimadas, poluição, urbanização, etc.) acaba por acarretar o isolamento de espécies animais ou vegetais, podendo levar a sua própria extinção. No caso do fragmento florestal, que é definido como qualquer área de vegetação natural contínua interrompido por barreiras antrópicas (estradas, culturas agrícolas, etc.), capazes de diminuir significativamente o fluxo de animais, pólen e/ou sementes (1990).

Constantemente, processos como o de urbanização e expansão da agricultura levam a um aumento nas taxas de desmatamentos, muitas vezes influenciando no isolamento geográfico das espécies de fauna e flora. Quanto menores e mais isolados forem os fragmentos florestais, mais facilmente as populações das espécies animais e vegetais entram em extinção (Ricklefs 1996). A fragmentação elimina o processo de acasalamento dos animais , o que acarreta à degradação dos habitats (Plummer \& Mann, 1995). Dessa forma, os corredores ecológicos passam a ter importância primordial nos programas de conservação da biodiversidade. Em outras palavras, a re-conexão de parte destes habitats isolados é um ponto estratégico para a conservação dos ambientes remanescentes.

Nesta linha de pensamento, os corredores ecológicos agem como conexões entre diferentes ambientes e/ou fragmentos florestais, permitindo o fluxo entre as populações silvestres, diminuindo os efeitos do isolamento e, conseqüentemente, a possibilidade de sobrevivência e manutenção do conjunto de subpopulações conectadas por indivíduos que se movem entre fragmentos (1991). Este corredor pode ser composto de pequenas áreas ambientalmente sustentáveis, tais como parques nacionais, reservas legais nas propriedades rurais, áreas de preservação permanente ao longo de rios e até mesmo as terras indígenas.

Entretanto, a criação de corredores baseia-se na premissa de que as ameaças múltiplas e crescentes para a proteção da biodiversidade exigem 
mais do que o estabelecimento de áreas protegidas, porém isoladas, normalmente cercadas por atividades antrópicas. A gestão inadequada das reservas ambientais e a falta de integração das populações locais tornam as tais áreas alvos de caça, exploração madeireira, mineração, assentamentos rurais, entre outros.

O fundamento legal dos corredores ecológicos encontra-se na lei $\mathrm{n}^{\mathrm{o}}$. 9985/2000 que constitui o SNUC (Sistema Nacional de Unidades de Conservação), e na resolução CONAMA (Conselho Nacional do Meio Ambiente) $n^{\circ}$. 09/1996, sendo o IBAMA (Instituto Brasileiro do Meio Ambiente e dos Recursos Naturais Renováveis) responsável pela implementação de corredores ecológicos no Brasil. Os corredores devem ser dimensionados e administrados para garantir que espécies da fauna e flora possam sobreviver e continuar seus processos biológicos normais (i.e. sobrevivência e reprodução).

A delimitação de corredores ecológicos no Brasil tem sido definida por estudos científicos onde, inicialmente, se avalia a representabilidade dos ecossistemas em relação às unidades de conservação e aos tipos fisionômicos existentes. Os resultados desse estudo determinam o grau de prioridade para a conservação, sem necessariamente passar pelo completo isolamento de partes do ecossistema em questão, mas sim por um manejo adequado das comunidades humanas mais próximas, seguindo as determinações legais para a ocupação e proteção da biodiversidade.

\section{O Corredor Ecológico Paranã-Pireneus}

O Corredor Ecológico Paranã-Pireneus, projeto homônimo em fase de implantação, refere-se a um limite geográfico que engloba parte dos estados de Tocantins, Goiás e Distrito Federal, com uma área aproximada de 10 milhões de hectares. Produto de uma cooperação internacional entre o Brasil (Ministério do Meio Ambiente/IBAMA) e o Japão (JICA - Agência de Cooperação Internacional do Japão).

O projeto tem como finalidade integrar as comunidades locais na área do corredor, com orientação a um manejo sustentável dos recursos naturais, além de capacitar e implementar programas de educação ambiental como forma de garantir a conservação da biodiversidade no bioma Cerrado.

No Estado de Goiás, o Corredor Ecológico Paranã-Pireneus ocupa

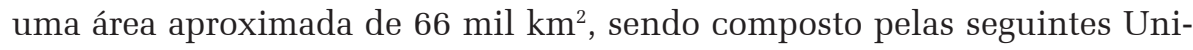
dades de Conservação, conforme (Figura 1). 
1. Região da APA do Pouso Alto / Chapada dos Veadeiros;

2. Região da APA da Serra Geral de Goiás;

3. Região da APA Nascentes do Rio Vermelho;

4. Região da APA do Planalto Central;

5. Região dA APA da Serra dos Pireneus.

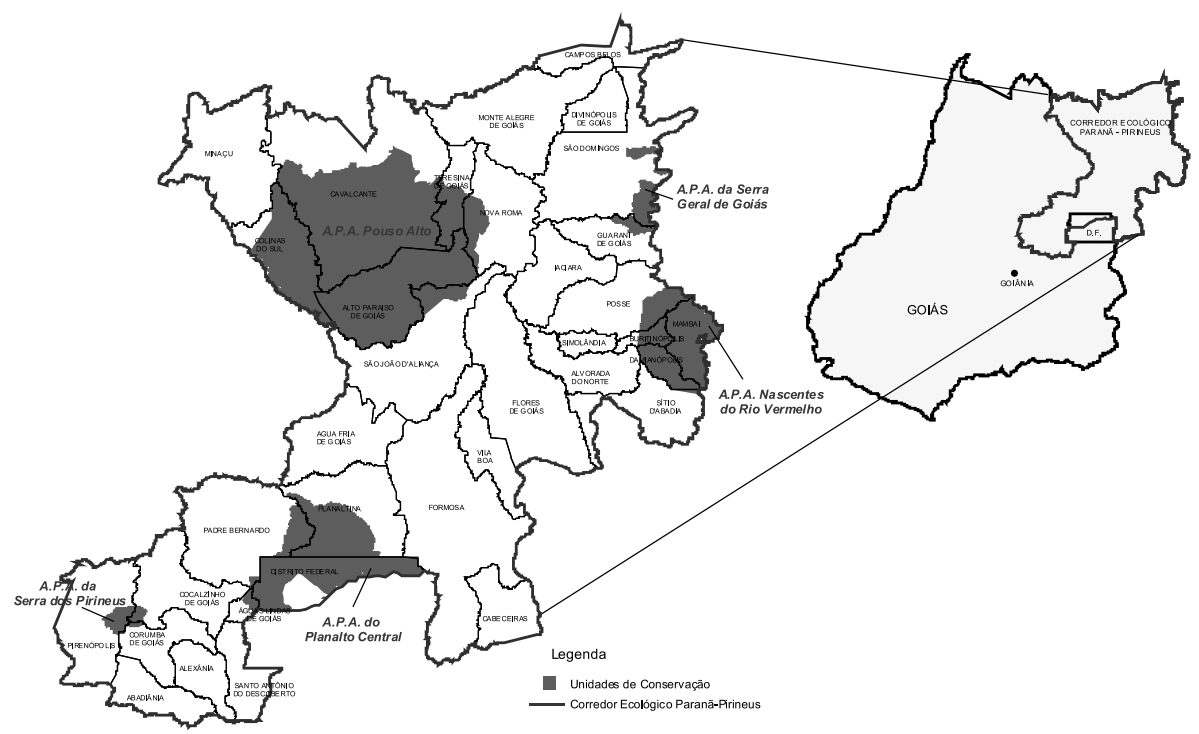

Figura 1. Inserção do Corredor Ecológico Paranã-Pireneus e respectivas Unidades de Conservação no Estado de Goiás.

\section{Abordagem metodológica}

\section{Área de Estudo}

Para os propósitos deste estudo, limitamos as análises ao limite do Corredor Ecológico Paranã-Pireneus, no Estado de Goiás, com uma área aproximada de 66 mil $\mathrm{km}^{2}$. A maior parte do corredor está localizada na região nordeste do estado, compreendida entre as Latitudes Sul $16^{\circ} 07^{\prime} 38$ ” / $12^{\circ} 55^{\prime} 07^{\prime \prime}$ e Longitudes Oeste 49 $11^{\circ} 47^{\prime \prime} / 46^{\circ} 07^{\prime} 06^{\prime \prime}$ (Figura 1).

O Corredor Ecológico Paranã-Pireneus em Goiás é composto por 34 municípios, com uma população de 605 mil habitantes (excluindo-se o Dis- 
trito Federal), sendo 122 mil vivendo na zona rural e 483 mil na zona urbana. O município com a menor densidade demográfica é Cavalcante, com 1,3 hab/ $\mathrm{km}^{2}$, enquanto o maior é Águas Lindas de Goiás, com 549,1 hab/km² (PNUD et al., 2000).

As atividades econômicas que se destacam na região são a pecuária e a agricultura, respectivamente $25,9 \%$ e 5,15\% (SIEG, 2006). O ecoturismo aparece ainda como uma atividade incipiente, mas de grande potencial. Atividades de carvoarias também são atuantes, ainda que de forma ilegal, causando enormes danos ao meio ambiente. De acordo com o IBAMA/GO, Mambaí é o município com o maior número de carvoarias no estado (15), seguido por Flores de Goiás (8) e a exploração já atinge os municípios de Sítio D’Abadia, Damianópolis, Posse e Colinas do Sul (2004).

Especificamente em relação ao ecoturismo, este é realizado normalmente nos parques da região, como o Parque Nacional Chapada dos Veadeiros, Parque Estadual dos Pirineus, Parque Estadual de Terra Ronca, Parque Municipal Ecológico Mata da Bica, Parque Municipal do Distrito de São Jorge, Parque Municipal Abílio Herculano Szervimsks, Parque Municipal Lavapés, todos relevantes, do ponto de vista econômico e ambiental, para os municípios de Alto Paraíso de Goiás, Cavalcante, Pirenópolis, Cocalzinho de Goiás, Corumbá de Goiás, Guarani de Goiás e Formosa.

\section{Base de Dados e Procedimentos de Análise}

Umas das principais bases de dados deste estudo diz respeito às imagens de satélite obtidas pelo sensor MODIS (MODerate resolution Imaging Spectroradiometer), à bordo da plataforma orbital TERRA (mais informações em http://modis.gsfc.nasa.gov/; Ferreira et al., 2006a; Ferreira et al., 2007). Dentre os produtos do MODIS, foi utilizado o MOD13Q1 (imagens índice de vegetação NDVI, 250 metros, 16 dias), disponibilizado gratuitamente pela internet no portal EOS/NASA (http://edcimswww.cr.usgs.gov/pub/imswelcome/). Estas imagens são fornecidas com georeferenciamento e corrigidas para os efeitos atmosféricos (nuvens, aerossóis e sombras).

As cenas MODIS (órbita/ponto h13v10), referente ao período de 2001 a 2006 (sempre no mês de outubro), foram processadas pelo Sistema Integrado de Alerta de Desmatamentos (SIAD) com o objetivo de detectar mudanças na cobertura vegetal (possíveis desmatamentos) para a área de estudo (mais informações em http://www.lapig.iesa.ufg.br/siadgoias/; Ferreira et al., 2004; Ferreira et al., 2006b). 
Para a detecção dos possíveis desmatamentos, foram adotadas as seguintes regras: área mínima de 50 hectares (área mínima de mudança na paisagem a ser detectada) e o limiar de mudança na paisagem de $30 \%$ (i.e. alteração mínima na cobertura vegetal a ser detectada). Nesta etapa de detecção, somente as imagens índice de vegetação NDVI (Normalized Difference Vegetation Index ou Índice de Vegetação por Diferença Normalizada) são analisadas, buscando-se a redução da biomassa entre duas datas (ex. outubro ano 1 - outubro ano 2).

Assim, o procedimento foi repetido para os anos 2001 - 2002, 2002 2003, 2003 - 2004, 2004 - 2005 e 2005 - 2006, completando-se os períodos de análise. Por fim, todos os prováveis desmatamentos detectados para todo o estado de Goiás foram filtrados de acordo com o limite do Corredor Ecológico Paranã-Pireneus (área de estudo).

Os dados de prováveis desmatamentos foram integrados com outras bases de dados de Goiás (restritas à área de estudo), tais como o mapa de limite político municipal e o mapa de uso do solo e de remanescentes vegetais para o estado. Especificamente ao mapa de cobertura vegetal, o mesmo tratase de uma compilação dos dados digitais elaborados no âmbito do projeto "Identificação de Áreas Prioritárias para a Conservação da Biodiversidade no Estado de Goiás” (Consórcio WWF/Imagem, sob coordenação da Agência Goiana de Meio Ambiente), na escala original 1:250.000 (Sano et al., 2006), disponibilizados atualmente nos Sistemas de Informações Estatísticas e Geográficas do Estado de Goiás (SIEG - www.sieg.go.gov.br).

Outra base de dados importante para a complementação deste estudo foi a análise sócio-econômica para os municípios goianos no corredor Paranã-Pireneus, representado aqui pelo Índice de Desenvolvimento Humano (IDH), Índice de Pobreza e Índice de GINI (referentes ao ano de 2000). Estes dados foram extraídos do Atlas de Desenvolvimento Humano no Brasil (PNUD et al., 2002), espacializados para os municípios em questão, e correlacionados com os valores de desmatamentos para os períodos analisados.

Numa breve descrição dos índices estudados, o IDH é um indicador elaborado pelo Programa das Nações Unidas para o Desenvolvimento (PNUD), o qual sintetiza três índices: escolaridade, renda per capta e longevidade. O intervalo de valores varia entre 0 (zero) e 1, onde 0 representa o mais baixo cenário de desenvolvimento, e 1 o mais alto cenário de desenvolvimento.

O Índice de Pobreza varia de 0 a 100\%, indicando a proporção de pessoas vivendo abaixo da linha de pobreza no Brasil, fixada (em R \$) de acordo com a metade do valor de um salário mínimo no país (em 2000, esta linha de pobreza correspondia a $\mathrm{R} \$ 75,00)$. 
O Índice de GINI descreve a concentração de renda para uma dada sociedade, onde 0 (zero) representaria, de forma hipotética, uma renda igualmente distribuída entre os indivíduos, e, 1 indicaria a concentração de toda a renda por um único indivíduo.

Todas as análises foram realizadas nos Sistemas de Informações Geográficas (SIG), empregando-se os softwares ArcGIS (ESRI) e ENVI (RSI), disponibilizados pelo Laboratório de Processamentos de Imagens e Geoprocessamento da Universidade Federal de Goiás (LAPIG/UFG).

\section{Resultados}

\section{Análise dos Desmatamentos}

Em relação às mudanças na paisagem observadas pelo SIAD para a região do Corredor Ecológico Paranã-Pireneus, no Estado de Goiás, detectouse a área de possíveis desmatamentos conforme metodologia descrita, para o período histórico entre 2001 e 2006. A tabela 1 indica a área destas detecções, por município.

Tabela 1. Área dos prováveis desmatamentos ocorridos no Corredor Ecológico Paranã-Pireneus, entre 2001 e 2006. Dados obtidos pelo Sistema Integrado de Alerta de Desmatamentos (SIAD - Goiás).

\begin{tabular}{|c|c|c|c|c|c|c|c|}
\hline \multirow{2}{*}{ Município } & \multirow{2}{*}{$\begin{array}{r}\text { Área } \\
\left(\mathrm{km}^{2}\right)\end{array}$} & \multirow{2}{*}{$\begin{array}{r}\text { Remanescente } \\
\text { de Cerrado (\%) }\end{array}$} & \multicolumn{5}{|c|}{ Desmatamento $\left(\mathrm{km}^{2}\right)$} \\
\hline & & & $\begin{array}{r}2001 / \\
2002 \\
\end{array}$ & $\begin{array}{r}2002 / \\
2003 \\
\end{array}$ & $\begin{array}{r}2003 / \\
2004 \\
\end{array}$ & $\begin{array}{r}2004 / \\
2005 \\
\end{array}$ & $\begin{array}{r}2005 / \\
2006 \\
\end{array}$ \\
\hline Abadiânia & $1.047,70$ & $39,91 \%$ & 0,00 & 41,30 & 1,65 & 0,08 & 0,00 \\
\hline Água Fria de Goiás & $2.036,70$ & $48,87 \%$ & 140,72 & 117,69 & 29,64 & 13,93 & 1,72 \\
\hline Águas Lindas de Goiás & 191,90 & $63,91 \%$ & 1,27 & 3,33 & 1,32 & 0,00 & 0,00 \\
\hline Alexânia & 850,80 & $59,16 \%$ & 2,42 & 26,36 & 6,20 & 1,45 & 1,43 \\
\hline Alto Paraíso de Goiás & $2.603,40$ & $84,13 \%$ & 191,82 & 113,17 & 143,97 & 1,11 & 3,06 \\
\hline Alvorada do Norte & $1.296,60$ & $47,73 \%$ & 13,20 & 15,48 & 5,27 & 3,44 & 0,00 \\
\hline Buritinópolis & 269,10 & $21,93 \%$ & 0,00 & 0,96 & 0,00 & 0,00 & 0,00 \\
\hline Cabeceiras & $1.117,40$ & $29,61 \%$ & 5,62 & 5,62 & 1,98 & 4,30 & 0,00 \\
\hline Campos Belos & 785,80 & $23,07 \%$ & 12,22 & 3,01 & 12,91 & 0,73 & 3,18 \\
\hline Cavalcante & $6.979,50$ & $90,48 \%$ & 531,25 & 311,12 & 212,82 & 52,97 & 49,12 \\
\hline
\end{tabular}




\begin{tabular}{|l|r|r|r|r|r|r|r|}
\hline Cocalzinho de Goiás & $1.794,30$ & $72,61 \%$ & 21,59 & 79,93 & 25,14 & 6,12 & 0,00 \\
\hline Colinas do Sul & $1.714,50$ & $78,05 \%$ & 156,53 & 13,83 & 124,69 & 4,78 & 0,00 \\
\hline Corumbá de Goiás & $1.066,20$ & $49,38 \%$ & 2,32 & 28,04 & 4,80 & 0,00 & 0,00 \\
\hline Damianópolis & 416,90 & $32,38 \%$ & 0,83 & 1,22 & 0,00 & 0,00 & 0,00 \\
\hline Divinópolis de Goiás & 834,30 & $77,03 \%$ & 5,74 & 51,86 & 9,60 & 0,00 & 6,41 \\
\hline Flores de Goiás & $3.722,80$ & $61,44 \%$ & 20,89 & 140,48 & 52,72 & 3,66 & 0,00 \\
\hline Formosa & $5.827,70$ & $50,66 \%$ & 280,32 & 103,32 & 283,43 & 34,49 & 7,18 \\
\hline Guarani de Goiás & $1.233,80$ & $56,54 \%$ & 14,51 & 68,69 & 19,55 & 0,56 & 0,00 \\
\hline Iaciara & $1.631,30$ & $48,93 \%$ & 0,00 & 286,07 & 19,57 & 0,00 & 0,00 \\
\hline Mambaí & 862,70 & $41,35 \%$ & 12,50 & 10,97 & 16,83 & 19,30 & 4,30 \\
\hline Minaçu & $2.871,60$ & $39,28 \%$ & 339,73 & 48,58 & 94,10 & 7,82 & 5,57 \\
\hline Monte Alegre de Goiás & $3.131,50$ & $55,17 \%$ & 47,76 & 444,56 & 42,33 & 5,63 & 1,45 \\
\hline Nova Roma & $2.143,90$ & $77,50 \%$ & 123,90 & 56,82 & 18,90 & 1,26 & 3,96 \\
\hline Padre Bernardo & $3.148,90$ & $48,68 \%$ & 80,95 & 110,25 & 90,51 & 1,66 & 1,65 \\
\hline Pirenópolis & $2.189,40$ & $23,29 \%$ & 67,84 & 14,91 & 46,35 & 0,00 & 1,66 \\
\hline Planaltina & $2.547,70$ & $73,02 \%$ & 123,34 & 123,47 & 123,35 & 28,44 & 16,37 \\
\hline Posse & $1.961,90$ & $43,16 \%$ & 12,35 & 193,67 & 7,05 & 1,28 & 5,30 \\
\hline Sto Antônio do & 941,60 & $30,95 \%$ & 11,10 & 86,20 & 30,58 & 0,80 & 0,77 \\
\hline Descoberto & $3.308,00$ & $62,14 \%$ & 16,57 & 364,08 & 51,04 & 9,62 & 15,40 \\
\hline São Domingos & $3.339,50$ & $72,91 \%$ & 256,49 & 58,82 & 196,20 & 1,22 & 6,33 \\
\hline Simolândia d'Aliança & 344,00 & $71,77 \%$ & 0,00 & 54,04 & 0,00 & 0,00 & 0,00 \\
\hline Sítio d'Abadia & $1.571,50$ & $42,71 \%$ & 1,81 & 22,22 & 9,20 & 1,72 & 0,00 \\
\hline Teresina de Goiás & 777,50 & $99,44 \%$ & 35,46 & 4,63 & 12,69 & 1,36 & 2,46 \\
\hline Vila Boa & $1.064,00$ & $41,84 \%$ & 17,13 & 23,52 & 6,03 & 0,00 & 0,00 \\
\hline Total & $65.624,40$ & $59,36 \%$ & $2.548,20$ & $3.028,24$ & $1.700,43$ & 207,73 & 137,32 \\
\hline
\end{tabular}

* Municípios no Corredor Ecológico Paranã-Pireneus, no Estado de Goiás.

Em análise aos dados da tabela 1, no período de 2001 a 2006, os municípios de Cavalcante e Formosa foram os que mais apresentaram desmatamentos na área de estudo, com 1.157,28 km² e 708,74 km², respectivamente. Foi verificada também uma queda significativa da área de prováveis desmatamentos nesta região. Vários motivos podem explicar tal redução, dentre estes uma maior repressão dos órgãos de defesa ambiental (federal e estadual) às ações ilegais de desmatamentos, sobretudo nas áreas utilizadas por carvoarias. Alterações na economia neste período, com influência nos 
preços de commodities agrícolas (maiores quedas no ano de 2005), também favoreceram a esta redução nos desmatamentos. Somado a estes motivos, ocorreram ainda mudanças sazonais no Cerrado, possivelmente com anos mais secos ou chuvosos, o que influi na quantidade de detecções para cada período analisado. A figura 2 ilustra a distribuição das detecções na área de estudo.

Como era o esperado para a região mais preservada em termos ecológicos no Estado de Goiás, todos os 34 municípios apresentam, pelo menos, 20\% de sua área com remanescentes de Cerrado. Destes 34, apenas 17 apresentam uma área de remanescentes superior a 50\%, com destaque para os municípios de Teresina de Goiás e Cavalcante, que ainda possuem mais de $90 \%$ de sua cobertura vegetal nativa.

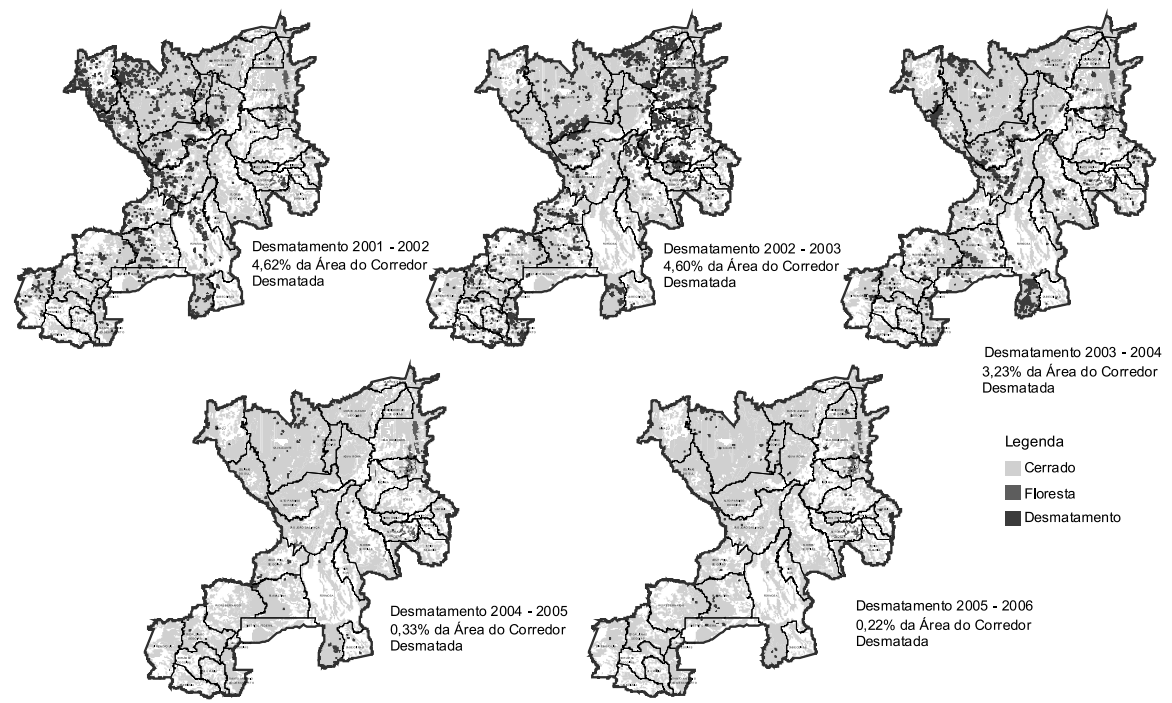

Figura 2. Distribuição dos prováveis desmatamentos no Corredor Ecológico Paranã-Pireneus no Período de 2001 a 2006, detectadas pelo SIAD.

O relevo acidentado, com áreas de acentuada declividade, é um fator natural que dificulta o avanço da agricultura mecanizada e da pastagem cultivada, favorecendo a preservação da cobertura vegetal nativa (et al., 2006c). A própria política de desenvolvimento do estado mantém esta região mais isolada em detrimento dos grandes centros produtores de Goiás, como Rio Verde e Goiânia. A figura 3 ilustra as classes de uso do solo e cobertura vegetal nativa para a área de estudo. 


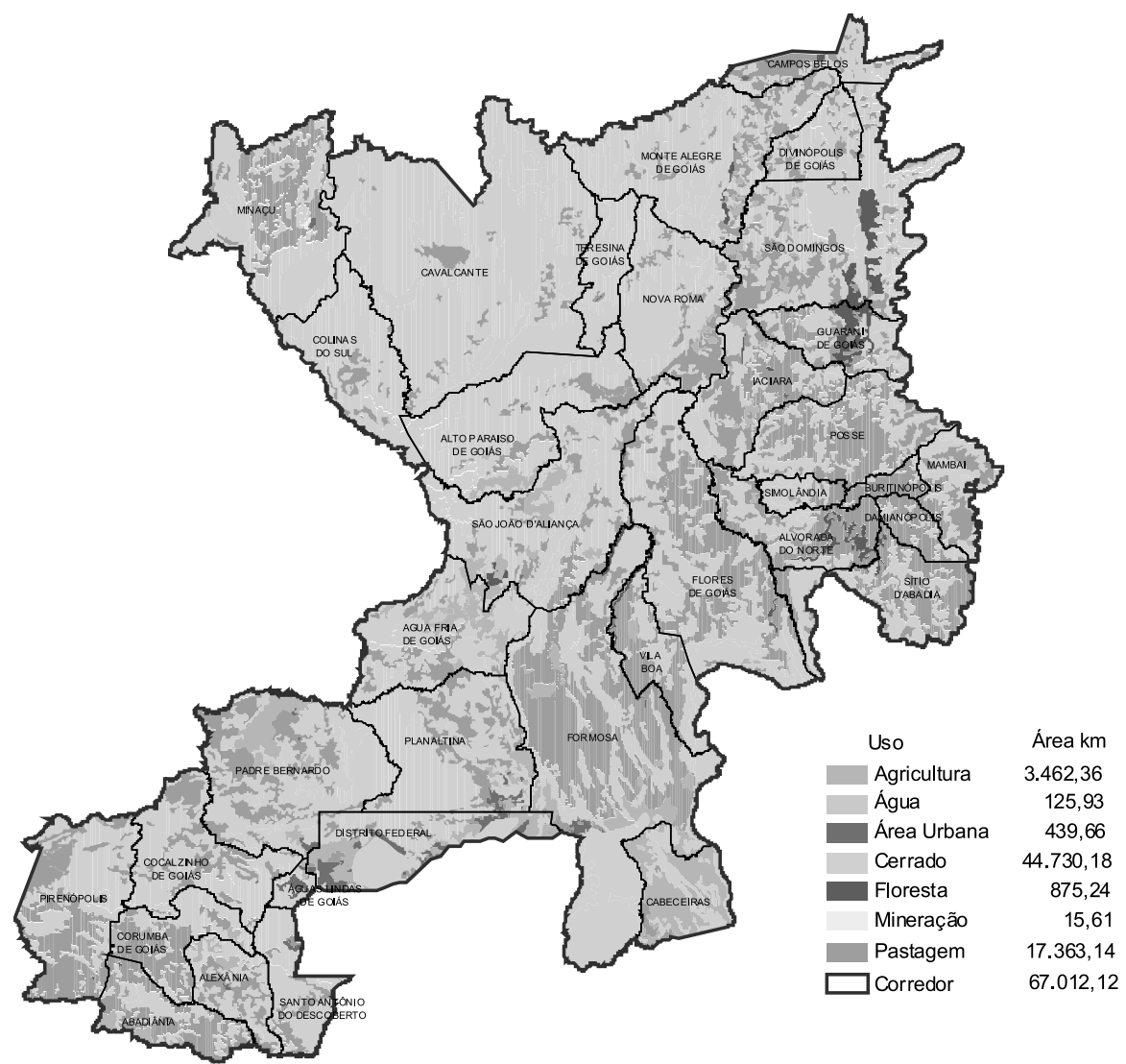

Figura 3. Uso do solo e cobertura vegetal nativa para o Corredor Ecológico Paranã-Pireneus. Fonte: base de dados do PDIAP (Sano et al., 2006).

\section{Análise Sócio-Econômica}

Especificamente em relação às análises sócio-econômicas, em geral os indicadores para esta região do corredor apontam, em média, um Índice de Desenvolvimento Humano Municipal (IDH-M) de 0,68, Índice de GINI de 0,60 e Intensidade de Pobreza de 50,9\%.

Com base na tabela 2, a qual compara os valores médios destes três índices com os demais municípios de Goiás e para o país como um todo, os índices obtidos para o corredor exibem um cenário preocupante e, ao 
mesmo tempo, desafiador, a medida em que estes apresentam os menores valores de IDH e maior proporção de pobres.

Tabela 2. Comparação do IDH-M, Índice de GINI e Intensidade de Pobreza para a área de estudo e demais localidades.

\begin{tabular}{|l|c|c|c|}
\hline \multicolumn{1}{|c|}{ LOCALIDADES } & IDH-M & Índice de GINI & Intensidade de Pobreza \\
\hline Corredor Ecológico Paranã-Pireneus (GO) & 0,68 & 0,60 & 50,90 \\
\hline Restante dos municípios de Goiás (GO) & 0,74 & 0,56 & 37,97 \\
\hline Brasil & 0,74 & 0,64 & 48,92 \\
\hline
\end{tabular}

Fonte: ATLAS do Desenvolvimento Humano. (valores médios para o ano de 2000).

Numa análise estadual, municípios como Goiânia e Rio Verde, com IDH-M de 0,83 e 0,81, respectivamente, apresentam estes valores acima da média estadual $(0,73)$ e nacional $(0,74)$, diferentemente dos municípios presentes na região do Corredor Ecológico Paranã-Pireneus, com IDH-M médio de 0,68. O mapa na figura 4 ilustra tal distribuição do IDH-M para o estado e corredor.

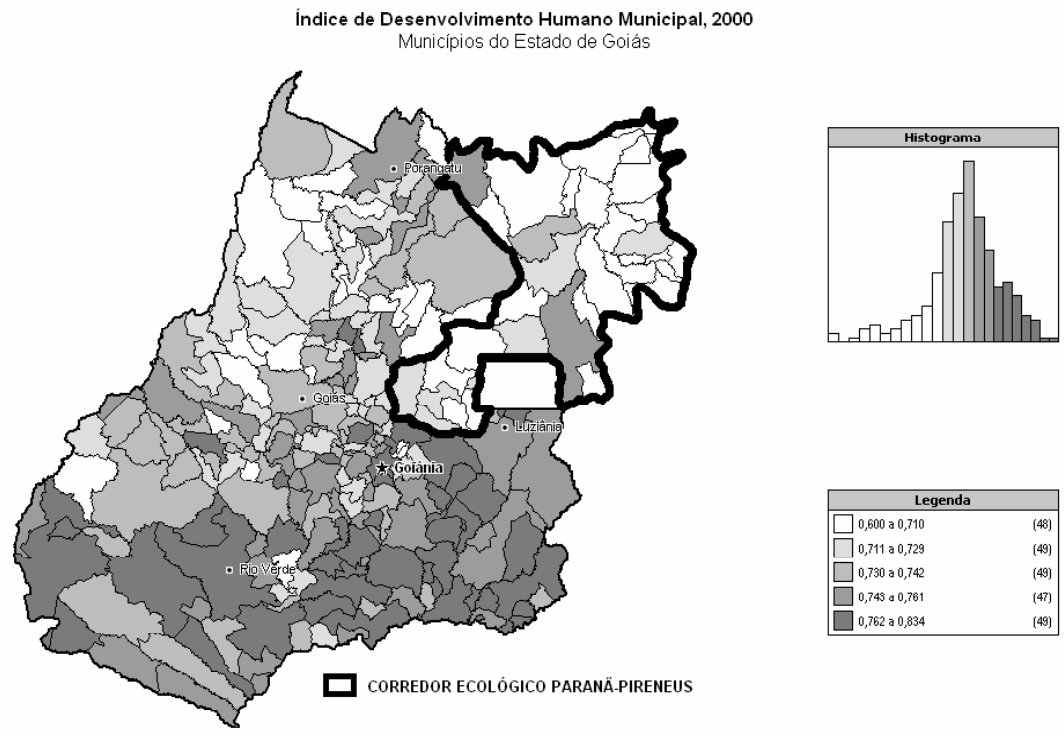

Figura 4. IDH-M para o Estado de Goiás, com destaque para o limite do Corredor Ecológico Paranã-Pireneus. 
Para uma melhor avaliação, dividiu-se a análise do Índice de Desenvolvimento Humano Municipal (IDH-M) em seus três componentes (educação, longevidade e renda per capta), como observado na tabela 3.

Pode-se observar que os valores médios do IDH-M na região do corredor (análise individual dos três componentes) estão abaixo da média estadual. Dentre estes componentes, o mais crítico é a renda per capta, apresentando média de 0,59 , enquanto que o menos crítico é o da educação, com média de 0,77, ainda abaixo da média das localidades de Brasília/DF (0,94), Goiânia $(0,93)$ e Rio Verde $(0,87)$.

Tabela 3. Índice de Desenvolvimento Humano Municipal (IDH-M, ano 2000), dividido em seus três componentes: educação, longevidade e renda per capta.

\begin{tabular}{|l|c|c|c|c|}
\hline \multicolumn{1}{|c|}{ LOCALIDADES } & IDH-M & $\begin{array}{c}\text { IDH-M } \\
\text { Educação }\end{array}$ & $\begin{array}{c}\text { IDH-M } \\
\text { Longevidade }\end{array}$ & $\begin{array}{c}\text { IDH-M } \\
\text { Renda }\end{array}$ \\
\hline Corredor Ecológico Paranã-Pireneus (GO) & 0,68 & 0,77 & 0,69 & 0,59 \\
\hline Goiânia (GO) & 0,83 & 0,93 & 0,75 & 0,81 \\
\hline Rio Verde (GO) & 0,81 & 0,87 & 0,80 & 0,75 \\
\hline Brasília (DF) & 0,84 & 0,94 & 0,76 & 0,84 \\
\hline Estado de Goiás & 0,73 & 0,82 & 0,73 & 0,65 \\
\hline Brasil & 0,74 & 0,83 & 0,71 & 0,68 \\
\hline
\end{tabular}

Fonte: ATLAS do Desenvolvimento Humano (valores médios para o ano de 2000).

Percebe-se, através da figura 5 que, a necessidade de geração de renda é um ponto crucial na maioria dos municípios que fazem parte do Corredor Ecológico Paranã-Pireneus, destacando-se, nesta situação, o município de Buritinópolis, que possui indicador abaixo de 0,50, ou seja, um nível bastante baixo para as médias estaduais e nacionais de IDH aceitáveis.

No tocante à educação, a situação dos municípios é mais promissora, com indicadores acima de 0,50. O município de Cavalcante é o que possui o menor índice de IDH-M Educação $(0,60)$. Esta categoria pode ser analisada pela figura 6. 

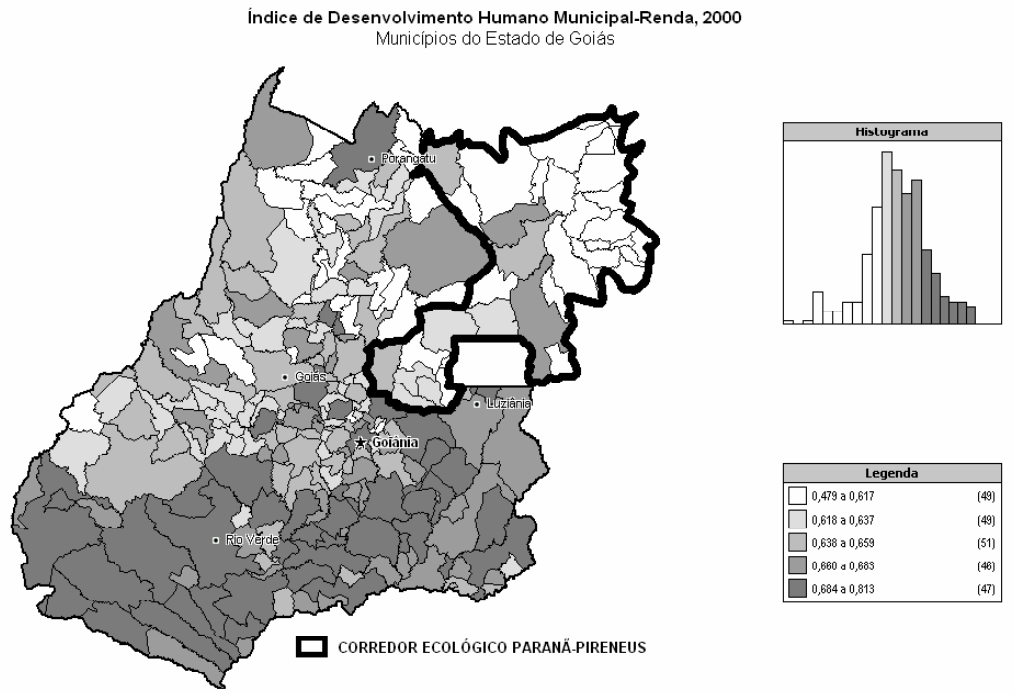

Figura 5. IDH-M, categoria Renda per capta, para o Estado de Goiás, com destaque para o limite do Corredor Ecológico Paranã-Pireneus.

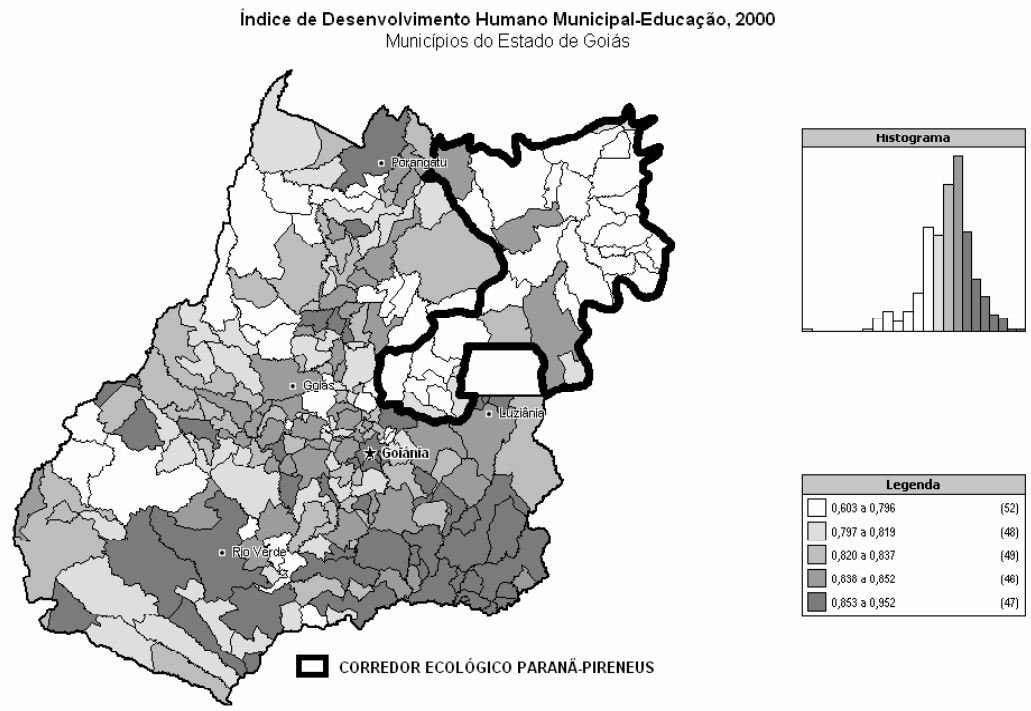

Figura 6. IDH-M, categoria Educação, para o Estado de Goiás, com destaque para o limite do Corredor Ecológico Paranã-Pireneus. 
Analisando o componente Longevidade, este se encontra numa situação mais próxima da média brasileira, com 0,69. Grande parte da região do corredor apresenta valores de longevidade baixos a médios, assim como o noroeste do estado de Goiás, em comparação aos valores mais altos para o restante do estado, conforme demonstrado pela figura 7.

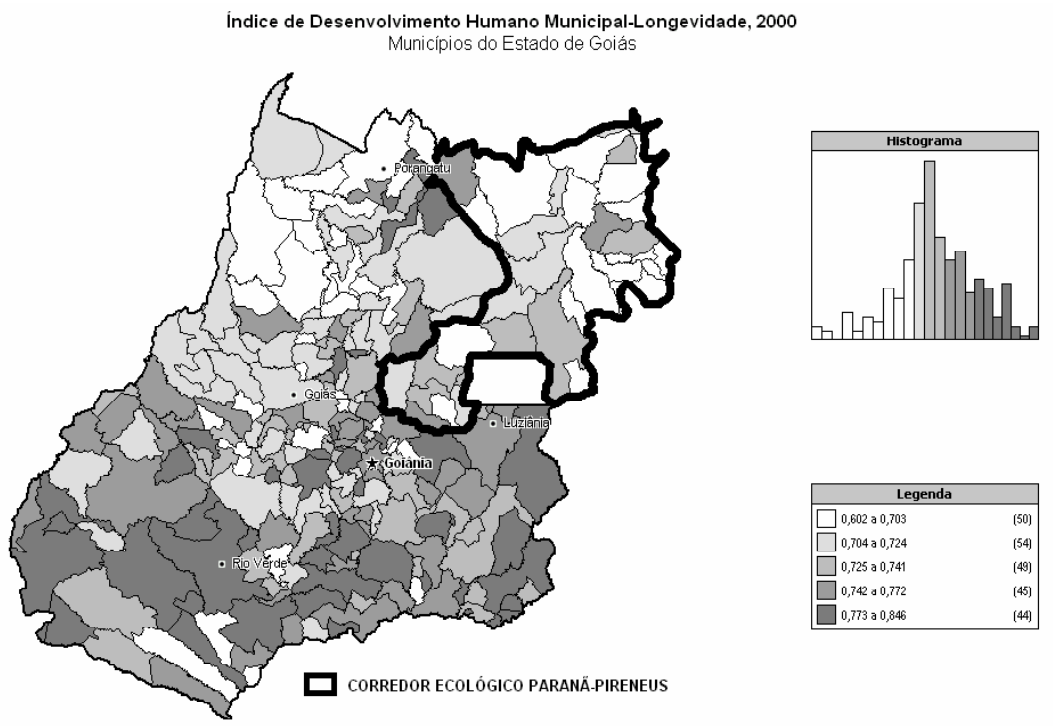

Figura 7. IDH-M - categoria Longevidade, para o Estado de Goiás, com destaque para o limite do Corredor Ecológico Paranã-Pireneus.

O Índice de GINI no Corredor Ecológico Paranã-Pireneus é de 0,60, isto é, acima da média estadual $(0,56)$, mas abaixo da média nacional $(0,64)$. Para este índice, quanto mais alto este valor, maior a concentração de renda. No momento, pode-se afirmar que a concentração de renda nos municípios do corredor ecológico está mais elevada do que deveria.

O município de Rio Verde (GO) apresenta o mesmo Índice de GINI $(0,60)$, enquanto Goiânia (GO) e Brasília (DF) apresentam médias mais altas do que aquelas do Corredor Ecológico Paranã-Pireneus, isto é, 0,61 e 0,64, respectivamente. A figura 8 ilustra tal distribuição.

A Intensidade da Pobreza na região do corredor ecológico apresenta média de 50,90\%, muito acima da média estadual $(39,79)$ e nacional $(48,92)$. Comparando-se com outras regiões mais desenvolvidas de Goiás, como Goiânia e Rio Verde, além de Brasília (DF), a região do corredor é a que, contra- 
ditoriamente, apresenta maior intensidade de pobreza e a maior cobertura remanescente de Cerrado.

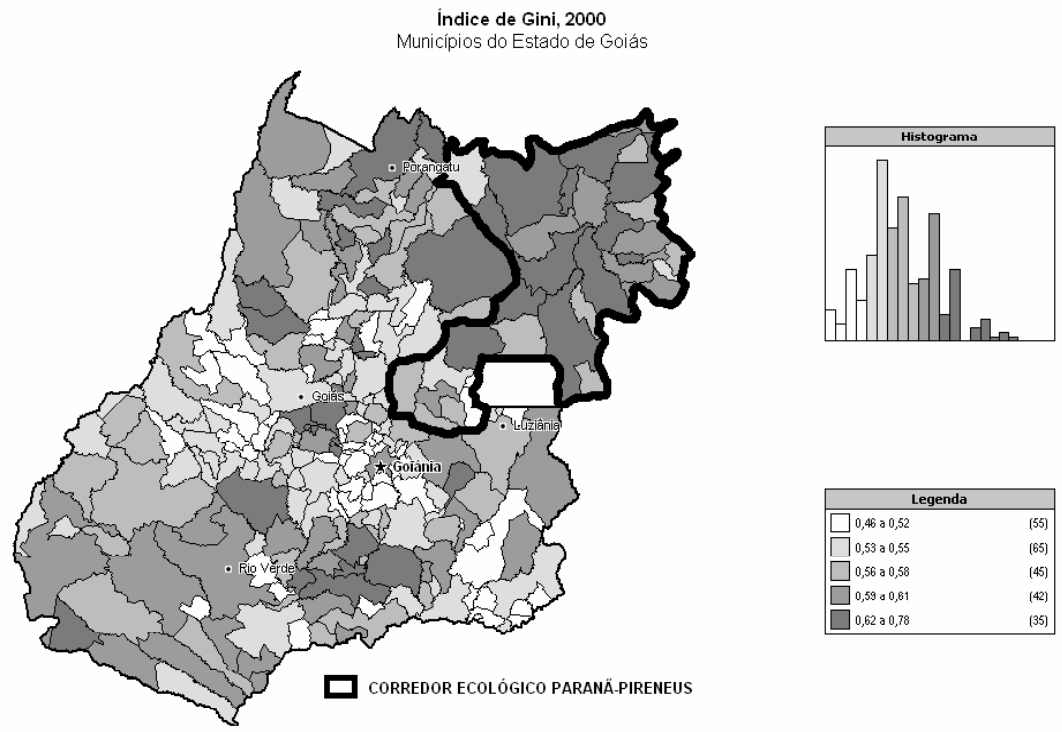

Figura 8. Índice de GINI para o Estado de Goiás, com destaque para o limite do Corredor Ecológico Paranã-Pireneus.

Estes dados, listados na tabela 4, assim como os demais apresentados, indicam que o chamado desenvolvimento sustentável ainda não ocorre verdadeiramente no Estado de Goiás, justamente porque as regiões mais desenvolvidas e com menor intensidade de pobres são justamente aquelas com maior grau de degradação do Cerrado e vice-versa. Por outro lado, a região de Rio Verde, por exemplo, apresenta um índice de GINI tão alto quanto àquele observado na região nordeste do estado (área do corredor ecológico), ou seja, as desigualdades persistem apesar do elevado desenvolvimento. Tão pouco vem sendo valorizada as localidades que mais preservam o Cerrado, caso dos municípios no corredor ecológico, os quais apresentam os valores de renda mais baixos do estado (tabela 3 ) e a intensidade de pobreza mais elevada (figura 9).

Assim, Novaes et al. (2006) discorrem sobre o assunto:

Em síntese, as populações mais empobrecidas do Estado podem, de forma significativa, ser encontradas nos locais com maior proporção de vegetação nativa. 
Mais ainda, quanto mais intensa essa pobreza, ou quanto mais pobres os pobres, independente da proporção de pobres na população, também maior é a presença de vegetação.

Tabela 4. Comparação do Índice de GINI e Intensidade de Pobreza para a área de estudo e demais localidades.

\begin{tabular}{|l|c|c|}
\hline \multicolumn{1}{|c|}{ LOCALIDADE } & Índice de GINI & Intensidade da Pobreza \\
\hline Corredor Ecológico Paranã-Pireneus (GO) & 0,60 & 50,90 \\
\hline Goiânia (GO) & 0,61 & 38,87 \\
\hline Rio Verde (GO) & 0,60 & 36,21 \\
\hline Brasília (DF) & 0,64 & 42,23 \\
\hline Goiás & 0,56 & 39,79 \\
\hline Brasil & 0,64 & 48,92 \\
\hline
\end{tabular}

Fonte: ATLAS do Desenvolvimento Humano (valores médios para o ano de 2000).
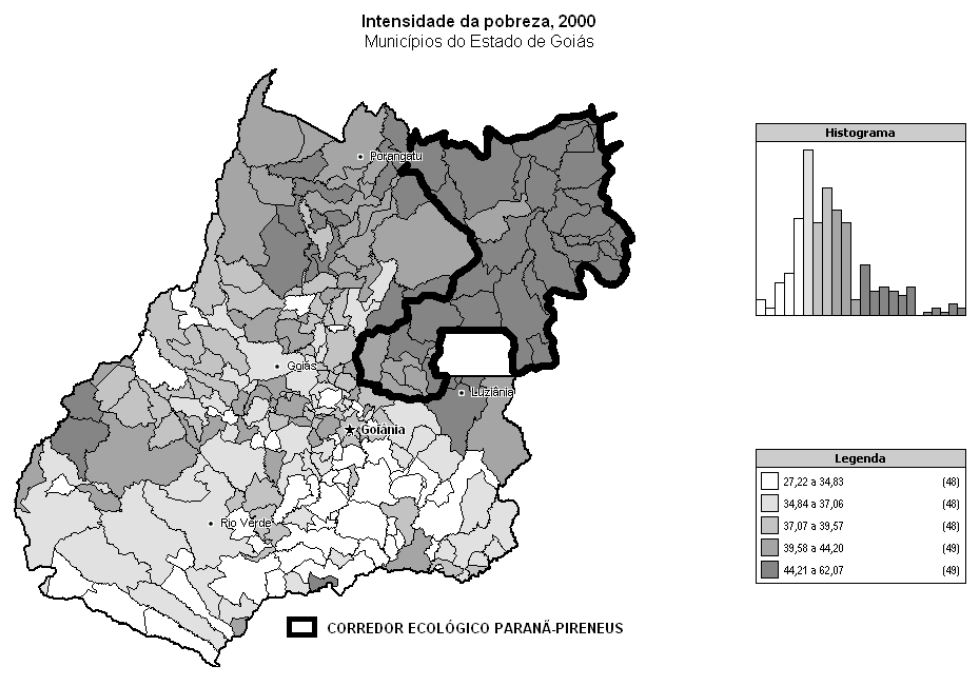

Figura 9. Intensidade de Pobreza para o Estado de Goiás, com destaque para o limite do Corredor Ecológico Paranã-Pireneus.

Quando confrontamos os dados sócio-econômicos com os de prováveis desmatamentos nos períodos analisados (tabela 5), observa-se que o município de Cavalcante apresentou em 2005/2006 a maior área de desma- 
tamento, correspondendo a 0,70\% da sua área geográfica. Este município é também o de maior Intensidade de Pobreza (60\%), o de menor Índice de Desenvolvimento Humano Municipal $(0,61)$, estando entre os municípios que possuem o maior índice de GINI $(0,63)$.

Por outro lado, o município de Nova Roma possui a menor área desmatada entre os 10 municípios listados (tabela 4), possui IDH-M igual à média do Corredor Ecológico Paranã-Pireneus $(0,68)$, com Índice de GINI $(0,59)$ abaixo da média de 0,60 . A Intensidade de Pobreza $(52,10)$ ainda está acima da média do corredor ecológico de 50,90.

Ainda com base na tabela 5, verifica-se que a grande parte dos prováveis desmatamentos que vem sendo realizada na região do Corredor Ecológico Paranã-Pireneus não resulta, necessariamente, em aumento de renda da população local. Portanto, o desmatamento não é condição sine qua non do crescimento econômico da região (Novaes et al., 2006).

Entretanto, os dados demonstram que a pobreza tão pouco é um fator significativo para a degradação ambiental no Corredor Ecológico ParanáPireneus. A maior presença de pobres na região pode estar contribuindo para a manutenção do Cerrado, já que eles próprios seriam os maiores prejudicados pela degradação deste meio ambiente (maior dependência dos rios e das matas preservadas).

Tabela 5. Lista dos 10 municípios com o maior de desmatamento no período de 2005/2006, em ordem decrescente.

\begin{tabular}{|c|c|c|c|c|c|}
\hline Município & $\begin{array}{c}\text { Desmatamento } \\
2005 / 2006 \\
\left(\mathrm{~km}^{2}\right)\end{array}$ & $\begin{array}{c}\text { Desmatamento } \\
2005 / 2006 \\
(\%)\end{array}$ & IDH-M & Índice de GINI & $\begin{array}{l}\text { Intensidade da } \\
\text { Pobreza }\end{array}$ \\
\hline Cavalcante & 49,12 & $0,70 \%$ & 0,61 & 0,63 & 60,00 \\
\hline Planaltina & 16,37 & $0,64 \%$ & 0,72 & 0,56 & 49,76 \\
\hline São Domingos & 15,40 & $0,47 \%$ & 0,63 & 0,63 & 57,57 \\
\hline Formosa & 7,18 & $0,12 \%$ & 0,75 & 0,63 & 51,19 \\
\hline Divinópolis de Goiás & 6,41 & $0,77 \%$ & 0,68 & 0,56 & 51,46 \\
\hline São João d'Aliança & 6,33 & $0,19 \%$ & 0,72 & 0,70 & 47,41 \\
\hline Minaçu & 5,57 & $0,19 \%$ & 0,75 & 0,54 & 51,85 \\
\hline Posse & 5,30 & $0,27 \%$ & 0,71 & 0,60 & 50,34 \\
\hline Mambaí & 4,30 & $0,50 \%$ & 0,65 & 0,56 & 52,82 \\
\hline Nova Roma & 3,96 & $0,18 \%$ & 0,68 & 0,59 & 52,10 \\
\hline
\end{tabular}

Fonte: ATLAS do Desenvolvimento Humano (valores médios para o ano de 2000). 


\section{Considerações finais}

De um modo geral, considera-se que o estado de pobreza de uma população leva à degradação ambiental. Todavia, em certas circunstâncias, como as que se verificam no Corredor Ecológico Paraná-Pireneus, o "atraso econômico" e a pobreza podem ter contribuído para certa forma de preservação. A população ainda é reduzida e isolada, com a principal atividade sendo a pecuária bovina praticada em pastagens naturais. Até a pouco tempo atrás, a população local retirava do Cerrado o que precisavam para subsistência, e não pensando em fins comerciais (ex. atividades madeireiras e carvoarias).

Atualmente, com a chegada do "progresso", a região passa a sofrer as conseqüências de um novo tipo de ocupação do solo, aumentando a pressão sobre os recursos naturais, com destaque para a cobertura nativa e os rios.

Uma auditoria recente feita pela AGMA constatou que as carvoarias estão servindo como intermediárias de grandes siderúrgicas para burlar a Lei Florestal e garantir a produção de carvão a baixo custo, empregando-se mão-de-obra barata (quando não escrava), sem qualquer preocupação com a preservação ambiental (Sano et al. 2006). Houve também a exploração de outras espécies, como a do Pequi, na região de Mambaí, e das sempre-vivas, na Chapada dos Veadeiros. Nessa fase, portanto, a falta de educação ambiental, aliada à pobreza da população local, deixa de “contribuir” para a preservação, com o registro cada vez mais freqüente de desmatamentos servindo a madeireiras ou carvoarias.

Nas regiões de Nova Roma, Iaciara, São João d'Aliança e Flores de Goiás já se torna comum a instalação de grandes e modernas fazendas de gado (ou frigoríficos), as quais aumentam a área de pastagem cultivada de forma extensiva. Com o avanço das lavouras comerciais, municípios como Flores de Goiás, Sítio d'Abadia e Alvorada do Norte passam a perder grandes áreas de Cerrado ou matas para implantar as lavouras mecanizadas de soja, por exemplo.

Para impedir o avanço na degradação do Cerrado em Goiás, se faz urgente a implantação e conservação do Corredor Ecológico Paranã-Pireneus, onde se localizam a maior parte de remanescente do estado.

Por fim, o sucesso de projetos como o do Corredor Ecológico ParanãPireneus é possível se forem adotadas estratégias voltadas para o desenvolvimento social da população local, valorizando o esclarecimento desta quanto à importância de se preservar a biodiversidade do Cerrado. 


\section{Agradecimentos}

Esta pesquisa contou com o apoio de dados e softwares do Laboratório de Processamento de Imagens e Geoprocessamento da Universidade Federal de Goiás (LAPIG/UFG). O $4^{\circ}$ autor é bolsista do Conselho Nacional de Desenvolvimento Científico e Tecnológico (CNPq).

\section{Referências}

Arruda, M. B., Dias, A., Latrubesse, E. M., Galinkin, M., Mendonça, A. F., Scardua, F. Projeto Corredor Ecológico Bananal - Araguaia. Brasília, DF. 2000.

Cardoso, E. S., Corrêa, R. S. Identificação de Corredores Ecológicos no Distrito Federal. In Anais do IV Congresso Brasileiro de Unidades de Conservação (pp. 241-249). Curitiba, PR. 2004.

Cerrado Vivo. Jornal da Reserva Particular do Patrimônio Natural. Publicação Trimestral do Projeto PNUD BRA/00/G35. Ano 2, n. 6 (pp. 1-4). Brasília, DF: Fundação FUNATURA. 2004.

Eiten G. (1993). Cerrado’s vegetation. In M. N. Pinto (Ed.), Cerrado: caracterização, ocupação e perspectivas (pp. 17-73). Brasília, DF: Ed. Universidade de Brasília.

Ferreira, L. G., Silva, A. A., Jesus, E. T. de, Sano, E. E., Shimabukuro, Y. E. Monitoramento Sistemático da Cobertura Vegetal no Bioma Cerrado através dos Índices de Vegetação Modis. In Anais XI SBSR (pp. 2729-2736). Belo Horizonte, MG: INPE. 2003.

Ferreira, M. E., Gomes, M. P., Aguiar, M. C. de, Ferreira, N. C., Ferreira Jr., L. G. Sistema Integrado de Alerta de Desmatamentos (SIAD) para o bioma Cerrado: uma nova abordagem para monitoramento sistemático e efetivo da região. In Anais $10^{\circ}$ Simpósio Ambientalista Brasileiro no Cerrado. Goiânia, GO. 2004.

Ferreira, M. E., Ferreira Jr., L. G., Peccinini, A. A., Huete, A. R. Análise Comparativa dos Produtos MODIS Ecologia para o Monitoramento Biofísico Ambiental do Bioma Cerrado. Revista Brasileira de Geofísica, 24, 251-260. 2006a.

Ferreira, M. E., Ferreira Jr., L. G., Ferreira, N. C. Cobertura vegetal remanescente em Goiás: distribuição, viabilidade ecológica e monitoramento. In L. G. Ferreira (Ed.), Conservação da Biodiversidade e Sustentabilidade Ambiental em Goiás: Prioridades, Estratégias e Perspectivas (pp. 148-164). Goiânia, GO: Universidade Federal de Goiás/Agência Ambiental/Banco Mundial. (no prelo). 2006c.

Ferreira, N. C., Ferreira, L. G., Ferreira, M. E. Sistema Integrado de Alerta de Desmatamentos do Estado de Goiás - SIAD-GO. Revista Infogeo. Curitiba, PR. 2006b.

Ferreira, N. C., Ferreira Jr., L. G., Huete, A. R, Ferreira, M. E. An operational deforestation mapping system using MODIS data and spatial context analysis. International Journal of Remote Sensing 28, 47-62. 2007.

Gilpin, M. E., Hanski, I. Metapopulation Dynamics. Empirical end Theoretical Investigations. Cambrige Univ. press, Cambrige and New York. 1991. 
Mantovani, J.E., Pereira, A. Estimativa da integridade da cobertura vegetal de cerrado através de dados TM/Landsat. In Anais $9^{\circ}$ Simpósio Brasileiro de Sensoriamento Remoto Santos, SP: INPE. 1998.

Myers, N., Mittermeier, R.A., Mittermeier, C.G., da Fonseca, G.A.B. \& Kent, J. Biodiversity hotspots for conservation priorities. Nature 403, 853-858. 2000.

Nepstad, D., Klink, C. A., UHL, C., Vieira, I. C., Lefebebvre, P., Pedlwski, M., Matricardi, E., Negreiros, G., Brown, I. F., Amaral, E., Homma, A., Walker, R. Land use in Amazônia and the Cerrado of Brazil, 49 (pp. 73-86), São Paulo, SP: Ciência \& Cultura. 1997.

Novaes, P. da C., Lobo, F., Ferreira, M. E. Pobreza, Desenvolvimento e Conservação da Biodiversidade em Goiás. In L. G. Ferreira (Ed.), Conservação da Biodiversidade e Sustentabilidade Ambiental em Goiás: Prioridades, Estratégias e Perspectivas (pp. 110-132). Goiânia, GO: Universidade Federal de Goiás/Agência Ambiental/Banco Mundial. (no prelo). 2006.

Plummer, M. L., Mann, C. C. Are wildlife corridors the right path? Science 270, 1428-1430. 1995.

PNUD, IPEAD e Fundação João Pinheiro Atlas do Desenvolvimento Humano no Brasil. Brasília: PNUD [Software]. URL http://www.pnud.org.br/atlas/. 2002.

Ricklefs, E. E. The Economy of Nature: a Textbook in Basic Ecology. University of Pennsylvania: Chiron Press. 1996.

Sano, E. E., Barcellos, A. O., \& Bezerra, H. S. Assessing the spatial distribution of cultivated pastures in the Brazilian savanna. Pasturas Tropicales 22 (3), 2-15. 2002.

Sano, E. E., Dambrós, L. A., Oliveira, G. C., Brites, R. S. Padrões de cobertura de solos do Estado de Goiás. In L. G. Ferreira (Ed.), Conservação da Biodiversidade e Sustentabilidade Ambiental em Goiás: Prioridades, Estratégias e Perspectivas (pp. 76-93). Goiânia, GO: Universidade Federal de Goiás/Agência Ambiental/Banco Mundial. (no prelo). 2006.

SIEG. Sistema Estadual de Estatística e de Informações Geográficas de Goiás http://www.sieg.go.gov.br. 2006.

Viana, V. M. Biologia e manejo de fragmentos florestais. In Anais $6^{\circ}$ Congresso Florestal Brasileiro (pp. 113-8). Campos do Jordão, SP. 1990.

Flávia C. Ribeiro - Agrimensor (CEFET/1997) e Especialista em Geoprocessamento (FAG0/2007).

Cristiane da C. Vilela - Agrônoma e Especialista em Geoprocessamento e Georeferenciamento (FAGO/2007).

Fátima M. Kowata - Engenheira Civil (FACEA/1996), Especialista em Engenharia de Segurança do Trabalho (UFG/1997) e Especialista em Geoprocessamento (FAG0/2007).

Manuel E. Ferreira - Geógrafo (UnB/2000), Mestre em Processamento de Dados em Geologia e Análise Ambiental (UnB/2003) e Doutorando em Ciências Ambientais (UFG). 